\title{
A proposed solution to a urological tightrope walk: The challenge of transition of spina bifida patients from pediatric to adult care in Ontario
}

\author{
Martin A. Koyle, MD, ,1,2 Nicole Golda, MD, ${ }^{2}$ Christopher Hillis, MD, ,23 Betty Oldershaw, RN, BScN, MSc QIPS; \\ Margaret DeMelo, RD, CDE, MSc,2 Jennifer Uyeno, PT, BScPT, MSc ${ }^{2}$
}

'The Hospital for Sick Children, Toronto, ON, Canada; ${ }^{2}$ Institute of Health Policy, Management and Evaluation, University of Toronto, Toronto, ON, Canada; ${ }^{3}$ Department of Oncology, McMaster University, Hamilton, ON, Canada

Cite as: Can Urol Assoc J 2016;10(9-10):E340-1. http://dx.doi.org/10.5489/cuaj.4206 Published online October 13, 2016

\section{Appendix A}

A member of our team had the opportunity to interview the mother of a person living with SB. Bonnie is now 26.

- Throughout infancy until she was 21, she was connected with Shriner's Hospital in Montreal. Locally, she was supported by the Children's Treatment Centre for PT, OT, Rehab services until the end of elementary school.

- Once she went to high school, the family noticed that there were limited opportunities for these services and were non-existent after Grade 9.

- She had experienced a spontaneous bladder perforation during a urodynamic test due to thin bladder wall that resulted in ileocystoplasty surgery while still a patient at Shriner's Hospital.

- She attended the Holland Bloorview Kids Rehab in Toronto for the "teen independence" program (remember they live in Chatham, so even transportation, time, cost was a huge issue) for a few summers; this was also a respite for mom, as the dad was diagnosed with pancreatic cancer at this time and mom worked fulltime in the emergency department.

- When discharged from the spina bifida clinic at Shriner's Hospital, she was referred to urologist in Ottawa for followup because of high risk for complications; this is where she hoped to live and attend university/college.

- While at college in Ottawa, brain herniation on a neurosurgical floor resulted in an unrecognized shunt failure, resulting in emergency burr holes. Her Glasgow coma scale of 3 was also unrecognized and she was resuscitated with compressed air rather than oxygen, resulting in hypoxia and residual developmental challenges.

- She had not been referred to either a neurologist or orthopedic surgeon or, even more importantly, a psychologist or therapist to assist with her psychosocial needs.

- On the positive side Bonnie experienced great support from educators in all phases of her education; nurturing, guiding, and supporting.

- She is now experiencing complications from childhood surgeries, i.e., bowel obstruction at the anastomosis site from bladder augmentation surgery done as child.

- Greater difficulty with fecal incontinence following ileal resection (once for bladder augmentation and then more recently for bowel obstruction).

- Bladder continence has been achieved with ileocystoplasty surgery, but at the expense of worsened fecal incontinence, which is a greater interference as a social disability, putting her further into social isolation.

- Bonnie's family has thankfully had a general physician who has been an advocate over the years.

- She requires attention for her developmental needs but does not fit the criteria for Community Living, so cannot access that care in Ottawa.

- Bonnie's mom was her main case worker and because she is a nurse connected with an acute care hospital, was able to navigate the system a bit better; she was able to get information that was required, but admits it is a convoluted system to navigate.

- Bonnnie has had four intensive care unit admissions in past 10 years requiring mechanical ventilation, mainly from sepsis; these surgeries have included bladder surgery, bowel obstruction for perforation, orthopedic fusions, etc., that she has recovered from, but were not smooth recoveries. 
- She tried university, but it became too challenging to attend; she had some developmental issues and difficulty with transportation and access.

- Living currently at PCIL Ottawa, "personal choice for independent living;" however, no personal choice for clients. Care is delivered to make work easier for staff, not clients. There are 90 people awaiting placement for assisted-living accommodations and a 7-10-year wait in Chatham for March of Dimes apartments.

- Bonnie's income is limited to social assistance and a small trust from her dad's estate; she doesn't have a lot of wiggle room for "fun stuff" and is constantly searching the job market, but again it is challenging to find an employer that will support her disability.

- She struggles with social isolation; friends are difficult to maintain, when asked out she has to consider access, handicap washrooms (benches would be nice in these restrooms so she doesn't have to lie on the floor in the restrooms to self-catheterize), what she should eat or drink and the effects from eating the "wrong" foods.

- Her mom has offered for her to come home, but she will be in the same isolated environment in Chatham, albeit with less resources.

- She does make arrangements to attend an infrequent concert or WWF event, as long as she does the research in advance; she has started to attend these events independently, which her mom is very proud of.

- The mom also noted in the SB circle in Chatham many teenagers and young adults in the community struggle with substance abuse or have ended up in nursing homes due to lack of family support.

- A final note: There are several resources for young children, but once they are post-secondary school and beyond, their needs seem to be forgotten; mom speaks about these children not expecting to survive past childhood, but healthcare has done a great job in providing them the best care as they have grown, but have not been able to predict or have the resources to continually support this group as adults.

- I look at Bonnie and ask her, "Do your happy days outnumber her unhappy days," and mostly, it is still yes, but she states "I strongly feel that Bonnie would not be alive today without my participation and advocacy. If she had not had a parent working in healthcare and knowing how to navigate the healthcare system, she would have died years ago."

- As far as costs, they are undetermined; some are covered, others are not, but the mom knows it is well over the $\$ 100000$ mark in additional care costs; the family has done what it has needed to do for Bonnie. 